\title{
Lavoura Arcaica: palavras e imagens bordadas no tecido invisível do tempo
}

\author{
Maria Ignês Carlos Magno* \\ Doutora em Ciências da Comunicação pela ECA/USP. \\ Professora do Mestrado em Comunicação da Universidade Anhembi Morumbi \\ e da Fundação Escola de Sociologia e Política de São Paulo. \\ E-mail: unsigster@gmail.com
}

Resumo: A autora propõe para esta edição da revista o filme Lavoura Arcaica, romance de Raduan Nassar transportado para o cinema por Luiz Fernando Carvalho. O objetivo é formular perguntas que instiguem a percepção da obra em todas as suas dimensões e as possíveis propostas de leituras e estudos, com o auxílio de diversos autores para selecionar os elementos-chave do filme.

Palavras-chave: cinema, fotografia, literatura, linguagem, ficção.
Abstract: The author proposes the discussion of the motion picture To the Left of the Father, Raduan Nassar's novel transposed to cinema by Luiz Fernando Carvalho. Her objective is to make possible raising up questions that incite the perception of the work in all of its dimensions and the formulation of proposals for interpretations and studies related to the film, with the help of several authors to select its key elements.

Keywords: cinema, photography, literature, language, fiction.

O tempo é um tecido invisível em que se pode bordar tudo, uma flor, um pássaro, uma dama. Um castelo, um túmulo. Também se pode bordar nada. Nada em cima de invisível é a mais sutil obra deste mundo, e acaso do outro.

Machado de Assis ${ }^{1}$

Guardar os vestígios do tempo, do rosto da mãe, enfraquecido pela dor, pela ausência do filho. Guardar, enfim, os momentos intermináveis da procura.

A procura da emoção da luz.

A mistura das tintas que, às vezes, tive a sensação de moer entre moletas de vidro, como os pintores renascentistas.

Walter Carvalho ${ }^{2}$

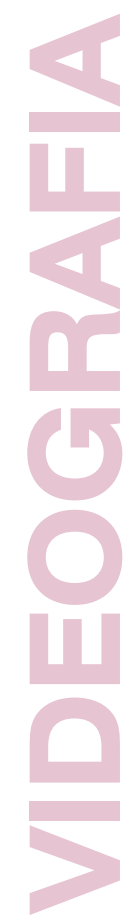

* Com a colaboração de Rogério Ferraraz, jornalista, doutor em Comunicação e Semiótica pela PUC-SP, mestre em Multimeios pela Unicamp, membro do Conselho Deliberativo da Socine e professor do Mestrado em Comunicação da Universidade Anhembi Morumbi. E-mail: rogerioferraraz@uol.com.br.

1. ASSIS, Machado de. Isaú e Jacó. São Paulo: Abril Cultural, 1984. p. 52.

2. CARVALHO, Walter. Fotografias de um filme: Lavoura Arcaica. São Paulo: Cosac \& Naify, 2003. 
Os olhos e as mãos percorriam a seção Cinema da biblioteca, quando a capa preta de um livro, cujo título, Fotografias de um filme, chamou a atenção. As delicadas imagens de mulheres em movimento de danças incentivavam os olhos a olhar sem pressa aquelas figuras em preto e branco. Em seguida um texto, o único escrito no livro todo. Mais que uma apresentação do trabalho, o texto aparecia como o relato de uma experiência única e as fotografias, mais que imagens de um filme, retratavam a força da emocionada experiência gravada para sempre na gramática do ser e na memória do fotógrafo Walter Carvalho. Imagens e palavras que aguçaram o ver e o rever o filme, bem como reler o livro Lavoura Arcaica de Raduan Nassar. E como não se trata só de mais um filme baseado em um romance, mas de palavras e imagens cuidadosamente trabalhadas por Raduan Nassar e Luiz Fernando Carvalho, no que Machado de Assis chamou de tecido invisivel do tempo, propomos para esta edição da revista o filme Lavoura Arcaica.

\section{FICHA TÉCNICA}

Título original: Lavoura Arcaica

Gênero: Drama

Direção: Luiz Fernando Carvalho

Roteiro: Luiz Fernando Carvalho

Produção: Luiz Fernando Carvalho

Música: Marco Antônio Guimarães

Fotografia: Walter Carvalho

Direção de Arte: Yurika Yamasaki

Figurino: Beth Filipecki

Ano de Lançamento (Brasil): 2001

Site oficial: <www.lavouraarcaica.com.br>

Estúdio: VideoFilmes

Distribuição: Riofilme

Censura: 16 anos

A história seria simples, se não fosse o avesso. O filme de Luiz Fernando Carvalho é homônimo do livro de Raduan Nassar. Versão transgressiva da parábola bíblica do filho pródigo que a casa retorna, o filme narra a história de André, o filho que se rebela contra as leis paternas e foge de casa. Mas esse não é o único motivo de sua fuga. André, ao contrariar os preceitos sagrados da religião e se apaixonar por sua irmã Ana, rompe também com uma das leis do Alcorão (Surata IV, 23), que proíbe o incesto. Refugiado em uma pensão, ele recebe a visita do irmão mais velho, Pedro, que tem a missão de trazê-lo de volta para casa. E o que seria motivo de alegria, para a família ansiosa pelo seu retorno, se transforma em tragédia, ao mostrar, na fragilidade das relações familiares e seus códigos, "um tipo específico de acontecimento e de 
reação que são genuinamente trágicos e [que a] longa tradição incorpora”, e não meramente a morte, o sofrimento ou uma reação a esses acontecimentos.

Muito já se escreveu sobre o primeiro longa-metragem de Luiz Fernando Carvalho; sobre a busca e a intencional manutenção da essência da obra de Raduan Nassar; a beleza da fotografia; a música e o som; as imagens que parecem pintadas sobre a película; a narração. O que descrever de uma obra cuja resposta à pergunta o que achou?, é sempre: Que lindo! ou Que bela fotografia! O que narrar sobre um filme que, mesmo se tendo prestado ao texto literário, conseguiu ser ele próprio uma fina escritura cinematográfica? O que sugerir para o exercício do olhar, quando se fica diante de uma película que coloca o espectador no extremo da sensação audiovisual? São perguntas que instigam a percepção da obra em todas as suas dimensões, já que ela é, por natureza, passível de interpretações. Pensando nessas questões e nas possíveis propostas de leituras e estudos, arriscamos propor, além de tudo o que já foi escrito, olhar para as imagens tecidas pela memória, que, por meio das palavras, nos explica, por exemplo, o motivo de a narração da experiência estar "unida ao corpo e à voz a uma presença real do sujeito na cena do passado", e mostrar, a partir de alguns autores, como fazer uma leitura de imagens. Pretendemos, além da apreensão de que é possível uma simbiose entre cinema/literatura, indicar como o cinema e a literatura dialogam com outras áreas no processo de criação. Tudo isso sem esquecer que literatura e cinema possuem gramáticas próprias e que o leitor de uma obra é também um produtor de sentidos.

Lavoura Arcaica é um romance memorialista, intimista, em que o narradorprotagonista André não é um herói, mas um ser convulsivo e em desespero, a quem acompanhamos desde as primeiras linhas do romance e da cena inicial do filme, quando ele é apresentado: "Os olhos no teto, a nudez dentro do quarto; róseo, azul ou violáceo, o quarto é inviolável; o quarto é individual, é um mundo, quarto-catedral, onde nas intermitências da angústia se colhe, de um áspero caule, na palma da mão, a rosa branca do desespero [...]"

A partir desse momento, por quase três horas, somos expostos ao relato confessional de André, que "sofre tudo o que diz, e diz tudo num registro de extremos" ${ }^{\prime \prime}$ e as "metáforas insurgentes, símbolos compulsivos, parábolas irônicas, recortes expressionistas acumulam-se em nossos olhos e ouvidos, quase sempre no andamento da mais profunda ansiedade"; então nossos sentidos, tal e qual aos do personagem, são aprisionados pelas imagens que ora acompanham, ora traduzem e essencialmente recriam a prosa poética do texto literário até seu trágico desfecho. Nesse tempo, e apesar de a razão querer se rebelar, sabemos também que estamos diante de um filme em que tudo é milimetricamente calculado, cada detalhe, cada elemento em cena, cada feixe de luz, cada som; em que tudo é muito correto e belo, nos dando a sensação de que, de certa forma, o filme parece ele mesmo preso e enclausurado (em suas composições visuais e sonoras), assim como seu personagem.
3. WILLIAMS, Raymond. Tragédia moderna. São Paulo: Cosac \& Naify, 2002. p. 31.

4. SARLO, Beatriz. Tempo passado: cultura da memória e guinada subjetiva. São Paulo/Belo Horizonte: Cia. das Letras/UFMG, 2007. p. 24

5. VILLAÇA, Alcides. Prefácio. As paixões e seus discursos. In: RODRIGUES, André Luis. Ritos da paixão em Lavoura arcaica. São Paulo: Editora da Universidade de São Paulo, 2006. p. 9.

6. Ibid.

7. Ibid. 
8. GULLAR, Ferreira. Barroco: olhar e vertigem. In: NOVAES Adauto (Org.). O olhar. São Paulo: Companhia das Letras, 1988. p. 219-220.

9. Ibid.
Nas inter-relações palavras e imagens, nas composições visuais e sonoras, nos jogos dos duplos, nos tempos que perpassam as memórias e os corpos, tecemos algumas outras reflexões sobre o filme. E uma delas, a mais diretamente reconhecida, é o jogo entre o claro e o escuro, que nos remete ao Barroco. No entanto, quando recuperamos a

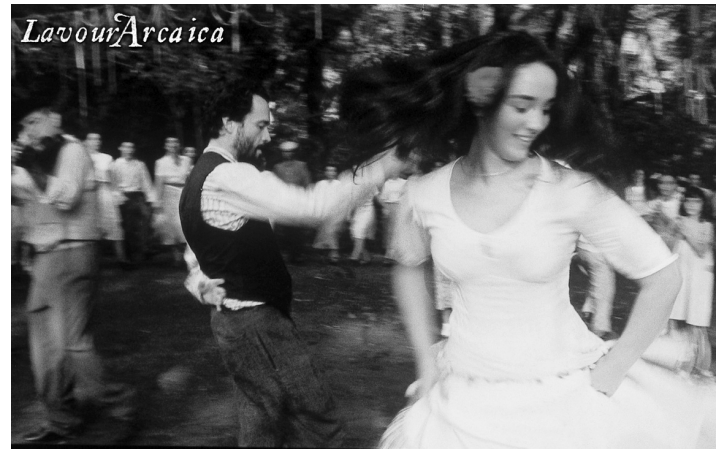
história do movimento Barroco, percebemos que apesar de terem sido muitos os barrocos, em suas diferentes versões, tensões e concepções artísticas, há uma constante: "a irregularidade, a assimetria, a paixão em lugar da racionalidade [...], é arte retórica e explosão da ilusão ótica que conduz ao delírio e à vertigem e consequentemente à ilusão"s.

Em Lavoura Arcaica, além dos

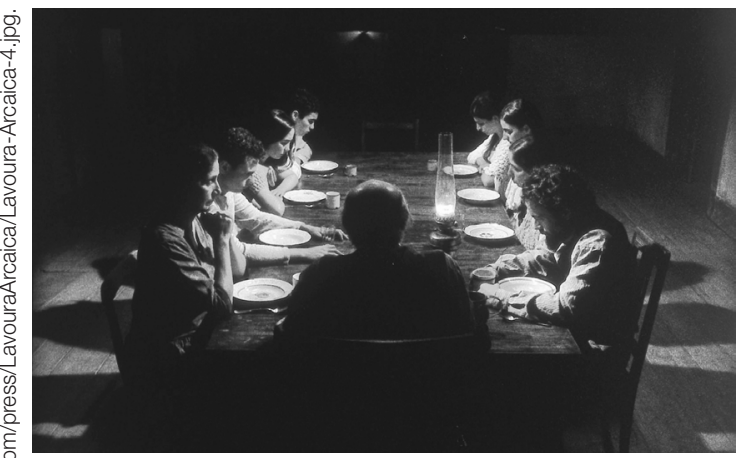
momentos em que a família está sentada em volta da mesa para ouvir os sermões do pai - e as composições do claro e escuro nos jogam de imediato nas cores e na atmosfera dos quadros barrocos -, a primeira hora do filme, na qual André aparece no quarto da pensão com o irmão Pedro, são rememorações que, ao mesmo tempo, mostram explosões de uma vivência em ebulição e um delírio verbal e corporal. Corpo jogado e encolhido no canto do quarto, em contorções, e um pé em primeiro plano, como se estivesse saindo do quadro, constituem imagens que nos lembram de outra característica barroca: a construção do olhar sobre o espaço, que, diferentemente de um quadro renascentista - em que tudo e todos os elementos estão submetidos a um espaço racional organizado -, "às vezes a figura posta em primeiro plano é como se fosse uma apreensão instantânea de uma cena, enquadrada por uma máquina fotográfica" ${ }^{3}$.

Outras são as mãos que tomam conta da tela, trêmulas, expressionistas, que a tudo querem agarrar, mas que são parte de um corpo em vertigem constante. $\mathrm{Ou}$, ainda, quando a câmera dirige nosso olhar para o rosto ou para os olhos de André, temos a sensação do movimento do pincel de Caravaggio, desviando a luz do centro

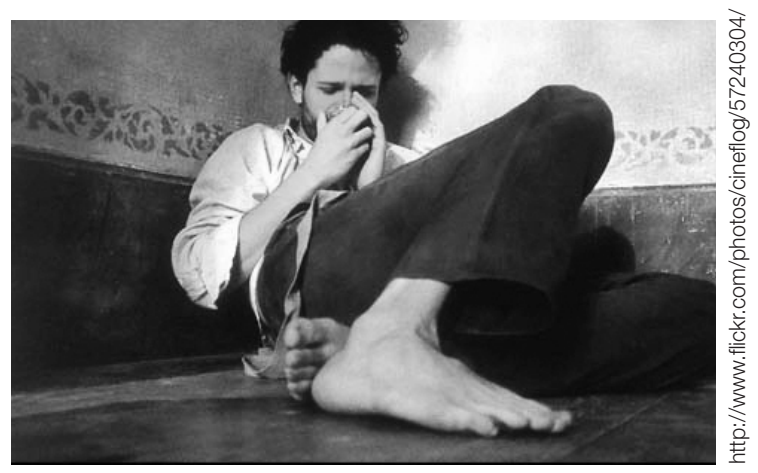


de uma cena para o detalhe que quer iluminar. E se a poética barroca está enraizada no catolicismo e em "uma literatura de sermão misterioso repleta de atrações festivas e ao mesmo tempo de açoites, uma invenção contínua para impedir que fiquem indiferentes aos que olham"10, é interessante observarmos outros aspectos na construção do texto e do filme. No terreno das imagens e dos textos bíblicos, a polaridade entre luz e trevas, o claro e o escuro, a ordem e a desordem são constantes. E pelo fato de os livros proféticos, em especial Isaías, e os livros sapenciais terem sido algumas das fontes mais importantes em que bebeu Raduan Nassar para a composição do sermão paterno - entre eles os Provérbios e o Eclesiástico, quando o pai se dirige ao filho ${ }^{11}$-, bem como pela forma como Luiz Fernando, à maneira de Caravaggio, faz as passagens entre o claro e o escuro, usando "um método de tudo ou nada, em que sombras densas contrastam bruscamente com áreas claras, quase sem transição"12, somos arremetidos para outros espaços e tempos.

Tempos de tradições, tempos de relatos, "de personagens, de relações entre ações voluntárias, abertas ou secretas. Tempo em que se fala do passado sem suspender o presente e, muitas vezes, implicando também o futuro"13; tempos em que o sagrado e o profano se misturam nos discursos e nos corpos; tempos das festas, seja como

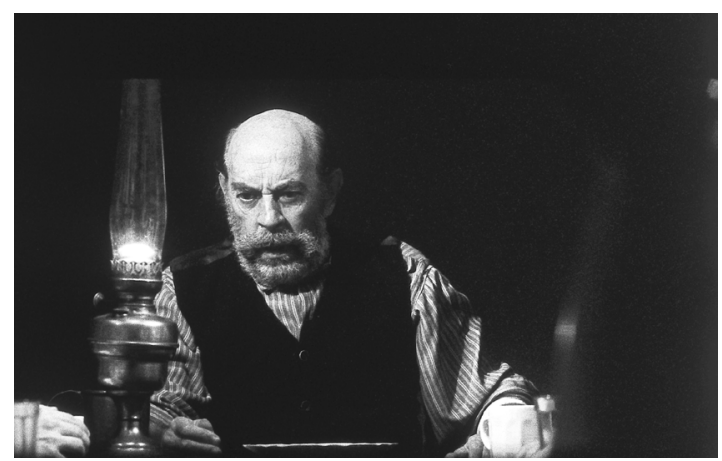
parte de uma longa tradição - em que "temporariamente são suspensas muitas das leis que regem a vida cotidiana da família [...], contrariamente à mesa regrada e sóbria dos dias de trabalho, os dias de festas primam pelo excesso: a carne assada, o vinho e as frutas em abundância" ${ }^{14}$-, seja para receber o filho pródigo, a qual o pai, na discussão motivada por Pedro, ao questionar a festa para o irmão, justifica ser necessária para receber o filho que estava morto. Retornos inscritos nas diferentes concepções de tempo, tanto ele mítico como histórico:

[...] no qual a ação dos afetos e da imaginação produz uma lógica própria [...] uma lógica que parece reproduzir os movimentos cíclicos do corpo e da natureza [...] o tempo reversível é, portanto, uma construção da percepção e da memória: supõe o tempo como sequência, mas o suprime enquanto o sujeito vive a simultaneidade ${ }^{15}$.

Há ainda a utilização da festa para mostrar, na figura de Ana, a tragédia anunciada. A mesma festa que no início do filme apresenta essa personagem ao espectador, descrita pelos olhos do irmão - "Ana, impaciente, impetuosa, o corpo de campônia, a flor vermelha feito um coalho de sangue prendendo de lado os cabelos negros e soltos"16 -, no final, revela o seu sacrifício, também sob os olhos e a narração de André. Dois tempos, duas percepções da realidade,
10. Ibid.

11. RODRIGUES. André Luis. Ritos da paixão em Lavoura arcaica. São Paulo: Editora da Universidade de São Paulo, 2006. p. 43.

12. GÊNIOS da Pintura. George de La Tour. São Paulo: Abril Cultural, v. 11, p. 5, 1967.

13. SARLO, op. cit., p. 12.

14. RODRIGUES, op. cit., p. 76.

15. BOSI, Alfredo. O tempo e os tempos. In: NOVAES, Adauto (Org.). Tempo e história. São Paulo: Companhia das Letras, 1992. p. 27.

16. RODRIGUES, op. cit., p. 79. 
17. Ibid., p. 95.

18. Ibid., p. 99.

19. Ibid., p. 60.

20. Ibid.

21. COSTA, Fernando Morais da. O som no cinema brasileiro: revisão de uma importância in deferida. Tese de doutorado. Niterói, Universidade Federal Fluminense, 2006. p. 221. duas narrações. Diferentemente da primeira festa, em que, ao olhar de longe sua irmã dançando, André tira os sapatos, as meias e afunda os pés nas folhas secas e na camada de espesso húmus, na segunda, quando Ana é morta pelo pai ao saber do incesto cometido, ele deita-se sob as folhas, cobre o corpo e o rosto e narra simplesmente. Para André, o que parecia se consumar era o destino, o que estava escrito no Livro Sagrado e no tempo visto por ele como demônio e recitado em um dos momentos do filme: "O tempo, o tempo é versátil, o tempo faz diabruras, o tempo brincava comigo ${ }^{17}$, [...] o tempo, o tempo, esse algoz às vezes suave, às vezes mais terrível, demônio absoluto $[\ldots . .]^{\prime 18}$. Destino que Nietzsche dizia conter uma estética do prazer trágico do sofrimento inevitável de um homem. No caso de André, o tempo era a sua dor maior, sua própria tragédia.

Antes de passarmos diretamente para os exemplos de análise fílmica do tempo, da voz e da narração em Lavoura Arcaica, realizadas por teóricos, historiadores e críticos de cinema, é interessante sabermos como o texto literário organiza os tempos da narrativa. A voz de André faz-se ouvir em diversos níveis:

[...] o primeiro destes é o da narrativa propriamente dita, isto é, André conta sua história. E mesmo esse nível fundamental não é unívoco, misturam-se nele: a narração de acontecimentos transcorridos num determinado tempo, que poderia ser chamado "tempo da ação", correspondente à chegada do irmão naquela pensão, ao diálogo que eles entretiveram em seguida e ao retorno à casa paterna, bem como aos acontecimentos que se seguiram a ele; e reminiscências de fatos passados antes da chegada de Pedro, anteriores ou simultâneos à própria fuga, que podem ser enquadrados no que se denominaria "tempo de rememorização", sem contar o "tempo da narração" de fato (o tempo presente), pois André narra acontecimentos passados de que detém todo o conhecimento ${ }^{19}$.

Se os tempos no discurso literário estão estruturados em tempo da ação nos capítulos ímpares e tempo da rememoração nos capítulos pares ${ }^{20}$, no cinema alguns exemplos podem esclarecer as construções ou soluções fílmicas para a narrativa literária. A angústia sentida na escuridão e nos espaços fechados do tempo presente é tensionada, na narrativa, pelo contraste com os planos abertos e luminosos da infância do personagem retratada através de flashbacks.

A ideia, o sentimento e as sensações que Lavoura Arcaica acarretam e atingem estão diretamente ligados ao tempo, à percepção do tempo, de sua passagem e de como ele se faz e se refaz na memória. Não à toa, na cena em que André se masturba convulsivamente num quarto de pensão, ouve-se o som da passagem de um trem, como se se aproximasse e se afastasse das lembranças do protagonista, incrustadas em sua mente e em seu corpo.

Fernando Morais da Costa destaca certas passagens no filme "em que os ruídos sobressaem" ${ }^{21}$. Dentre elas, a sequência inicial:

[...] André se masturba. Um primeiro plano localiza o corpo de Selton Mello no quarto. Os planos seguintes, extremamente próximos, fazem das partes do corpo que vemos uma massa de pouca definição, graças à falta de profundidade no foco e à escolha da lente. A trilha sonora é o som de um trem que se torna 
mais presente à medida que o corpo se retesa, e sai de cena à medida que o relaxamento vem. Na junção entre a imagem do corpo e o som do trem, um exercício de sincronia refinado: os apitos da máquina encaixam-se em cada abrir da boca, o corpo treme no mesmo ritmo do som. A partir de quando o trem some, surge a construção dos sons "naturais", do som ambiente do lugar da ação: pássaros, um cachorro. O próximo som completa a volta à realidade. Batem à porta insistentemente. É Pedro, irmão de André, que vem lhe buscar, de volta à casa.

Tal sequência já aponta para três elementos-chave da obra: a complexa utilização do som, conforme observado; a minuciosa composição visual e o tempo da cena; e o tema do retorno ao lar, à família. Aqui, trata-se mais de uma inversão (ou subversão, talvez) do mito da volta do filho pródigo: André, como ele mesmo define ao se lembrar da posição em que cada membro da família se sentava à mesa, pertencia ao galho da esquerda do pai, composto por sua mãe, por ele, Ana e Lula, o irmão caçula. Galho que carregava o "estigma da cicatriz, como se a mãe, que é por onde começava o segundo galho, fosse uma anomalia, uma protuberância mórbida pela carga de afeto" ${ }^{22}$.

Em Ensaio sobre a análise fílmica, Francis Vanoye e Anne Goliot-Lété ressaltam que a enunciação é uma "instância narradora fundamental [que] pode delegar seus poderes a um ou a vários narradores que se encarregam da totalidade ou de uma parte da narrativa"23. Os autores, retomando estudos de Christian Metz e de Michel Chion, destacam que esse narrador delegado pode assumir diversas formas, entre elas: o diegético, na voz de um ou mais personagens; o peridiegético, um observador fora da ação, mas que supostamente não esteja fora da diegese; e o extradiegético, um comentador externo. Vale lembrar que diegese é comumente usada como sinônimo de universo fictício ou ficcional. Porém, autores como Jacques Aumont, Alain Bergala, Michel Marie e Marc Vernet observam que:

[...] é preciso compreendê-la como o significado último da narrativa: é a ficção no momento em que não apenas ela se concretiza, mas também se torna uma. Sua acepção é, portanto, mais ampla do que a de história, que ela acaba englobando: é também tudo o que a história evoca ou provoca para o espectador ${ }^{24}$.

Em Lavoura Arcaica, trata-se claramente de um narrador diegético, André, que, por vezes, assume uma voz que Chion denominou de voz-eu, e Metz de justa-diegética. De acordo com Metz, "O personagem é diegético, mas a voz, como voz, não é completamente, pois não se mostra o narrador no ato de contar. [...] Essa voz [...] permite que um personagem da diegese dela saia ao mesmo tempo em que nela permanece" ${ }^{25}$. Parece ser exatamente esse um dos movimentos que a narração do filme de Carvalho percorre.

Além dessa constituição múltipla do narrador André, ainda temos no filme, em diversos momentos, a focalização mental, ou a voz interior do personagem. Ouvimos seu pensamento, suas ideias, enquanto o personagem mantém-se calado.
22. Ibid.

23. VANOYE, Francis; GOLIOT-LÉTÉ, Anne. Ensaio sobre a análise fílmica. 3. ed. Campinas: Papirus, 2005. p. 45.

24. AUMONT, Jacques et al. A estética do filme. Campinas: Papirus, 1995. p. 114.

25. METZ, apud VANOYE, Francis; GOLIOT-LÉTÉ, Anne. Ensaio sobre a análise fílmica, cit., p. 47. 
26. XAVIER, Ismail. A trama das vozes em Lavoura Arcaica: a dicção do conflito e a da elegia. In: FABRIS, Mariarosaria GARCIA, Wilton; CATANI, Afrânio Mendes (Org.) Estudos Socine de $\mathrm{Ci}$ nema: ano VI. São Paulo: Nojosa Edições, 2005. p. 18.

27. COSTA, op. cit., p. $220-221$.

28. XAVIER, op. cit., p. 14.

29. VILLAÇA, op. cit. p. 15.
Fernando Morais da Costa, partindo das observações de Ismail Xavier em artigo que analisa o uso da narração em Lavoura Arcaica, reflete justamente sobre a complexidade do jogo de vozes no filme - ou um torneio de palavras, retomando expressão utilizada por Xavier ${ }^{26}$ e citada por Costa.

Como diz Xavier, há uma distinção de tons entre o André que está em cena e o André que narra. A voz de Selton Mello quando está em quadro é muitas vezes gritada, exaltada, enquanto a narração over, em um tempo futuro com relação ao que se vê na imagem, é tranquila, não contém a revolta da primeira. Como agente complicador, a voz de André na narração por vezes é de Selton Mello, por vezes é do diretor, Luis Fernando Carvalho. Xavier nota ainda outra dicotomia, entre a loquacidade de André e o silêncio de Ana, sua irmã, objeto de seu desejo. Uma vez o ato proibido consumado, o silêncio total de Ana torna a exasperar André, que é tomado por longo arroubo verbal ${ }^{27}$.

O filme é repleto de imagens poéticas e líricas: elas muitas vezes representam aquilo que André metaforiza em relação a suas lembranças de infância. Um exemplo encontra-se quando André comenta que, quando criança, entrava na igreja feito um balão; há um corte para tomadas aéreas, com a câmera mostrando o campo até chegar e circundar a igreja. Num novo corte, vê-se ao fundo o grupo de irmãs subindo as escadas ao mesmo tempo em que surgem os pés do protagonista aterrissando em primeiro plano, como se pousasse na entrada da igreja.

Para Ismail Xavier,

Na disposição clara dos motivos, Lavoura Arcaica é filme clássico, pela força com que impõe sua diegese e o senso de continuidade, e pela forma como traduz as metáforas do romance. No entanto, do começo ao fim, é também um filme moderno em sua forma de trabalhar a duração da cena, o movimento do olhar, o andamento da fala, a impostação dos gestos tensos, com notável articulação entre o drama (a cena visível) e a narração em voz over, esta em disciplinada sintonia com a música de fundo. A relação entre voz e imagem (montagem vertical) envolve cotejos em que a experiência do tempo se faz complexa; no entanto, o filme dispõe os fatos segundo uma ordem inexorável que o jovem André intui, mas não aceita, vivendo momentos de tensão aguda que o outro André, o narrador invisível, parece ter superado em sua evocação reconciliada, própria a um momento já posterior à anagnorisis (reconhecimento) no curso da experiência trágica de que ele foi protagonista, mas não de todo herói, como se verá 28 .

Para Alcides Villaça,

[...] a mistura de gêneros, executada nesse amálgama de continuidade épica, de arrebatamento lírico, de enunciação reflexiva e de sentimento do mítico e do trágico, constitui uma predicação formal que guarda íntima correspondência com o cruzamento dos discursos, com o entroncamento dos tempos da memória e da ação, com um universo só aparentemente coeso e fechado, na verdade um reflexo deste novo mundo tão esclarecido, tão bárbaro, tão arcaico ${ }^{29}$. 
Se o romance é exigente, porque conta com um leitor "cuja sensibilidade se [ativa] plenamente na sintonia fina dos impulsos rítmico-melódicos, os quais estão na base da narração e constituem uma modalidade de fala e expectativa de escuta peculiares ao discurso da poesia"30; se o filme nos interessa, na medida em que podemos acompanhar como Luiz Fernando escutou a sofisticada prosa poética de Raduan, em que o lírico e o trágico se misturam na trama de uma tragédia familiar, e transformou essa fala e escuta na sua escrita cinematográfica, finalizamos este texto propondo, entre todas as outras possíveis leituras que o leitor-espectador poderá fazer das obras, um exercício sobre os processos de criação de Raduan e Luiz Fernando, acompanhando como, em constante e cuidadosos diálogos com pessoas, sensibilidades, tempos e memórias, teceram palavras e imagens; e, tentando entender, talvez, o emocionado texto de Walter Carvalho:

Muitas vezes, ao fim da tarde, quando regressávamos à fazenda em busca de repouso, assaltava-me a angústia sobre o resultado lavourado daquele dia. Mais que o resultado técnico obtido e apreendido nas latas de filme, o que me tomava era a vontade imensa de encontrar o desconhecido: um filme em carne viva ${ }^{31}$.

\section{REFERÊNCIAS BIBLIOGRÁFICAS}

ASSIS, Machado de. Isaú e Jacó. São Paulo: Abril Cultural, 1984.

AUMONT, Jacques et al. A estética do filme. Campinas: Papirus, 1995.

BOSI, Alfredo. O tempo e os tempos. In: NOVAES, Adauto (Org.). Tempo e história. São Paulo: Companhia das Letras, 1992.

CARVALHO, Walter. Fotografias de um filme: Lavoura Arcaica. São Paulo: Cosac \& Naify, 2003.

COSTA, Fernando Morais da. O som no cinema brasileiro: revisão de uma importância indeferida. Tese de doutorado. Niterói: Universidade Federal Fluminense, 2006.

GULLAR, Ferreira. Barroco: olhar e vertigem. In: NOVAES, Adauto (Org.). O olhar. São Paulo: Companhia das Letras, 1988.

RODRIGUES, André Luis. Ritos da paixão em Lavoura Arcaica. São Paulo: Editora da Universidade de São Paulo, 2006.

SARLO, Beatriz. Tempo passado: cultura da memória e guinada subjetiva. São Paulo/Belo Horizonte: Companhia das Letras/UFMG, 2007.

VANOYE, Francis; GOLIOT-LÉTÉ, Anne. Ensaio sobre a análise fílmica. 3. ed. Campinas: Papirus, 2005.

VILLAÇA, Alcides. Prefácio. As paixões e seus discursos. In: RODRIGUES, André Luis. Ritos da paixão em Lavoura Arcaica. São Paulo: Editora da Universidade de São Paulo, 2006.

30. Ibid., p. 16.

31. CARVALHO, Walter. Fotografias de um filme, cit., p. 29. 
comunicação \& educação • Ano XIV • Número 2 • maio/ago 2009

WILLIAMS, Raymond. Tragédia moderna. São Paulo: Cosac \& Naify, 2002.

XAVIER, Ismail. A trama das vozes em Lavoura Arcaica: a dicção do conflito e a da elegia. In: FABRIS, Mariarosaria; GARCIA, Wilton; CATANI, Afrânio Mendes (Org.). Estudos Socine de cinema: ano VI. São Paulo: Nojosa Edições, 2005. 